reskonferenz der amerikanischen Gesellschaft für Blutbanken sind zu richten an: American Association of Blood Banks, Miss Majorie Saunders, secretary, 3707 Gaston Avenue, Dallas, Texas, U.S.A. (Vorläufiges Programm siehe Anzeigenteil.)

Vom 9. bis 14. September 1956 findet in New York der Internationale Kongreß für Klinische Chemie statt. Alle Mitteilungen sind zu richten an: Dr. Harry Sobotka, The Mount Sinai Hospital, New York 29 (N.Y., U.S.A.).

Am 26. und 27. September 1956 findet in Rom unter dem Präsidium von Prof. E. Trabucchi der 4. Kongreß für Chemotherapie statt. Anschließend soll am 28. September 1956 ein internationales Symposium über Actinomycin unter dem Präsidium von Prof. Waksman abgehalten werden. Anfragen an die Italienische Vereinigung für Chemotherapie, Pharmakologisches Institut der Universität Mailand, Via Andrea del Sarto 21.

Im Rahmen des 31. Deutschen Gynäkologenkongresses 1956 in Heidelberg findet am 21. 9. 1956 ein Symposion über »Physiologie und Pathologie der Blutgerinnung in Schwangerschaft, Geburt und Wochenbett statt. Leitung: H. Schwalm, Mainz. I. Physiologie der Blutgerinnung in Schwangerschaft, Geburt und Wochenbett. Hauptreferat: H. Zilliacus, Helsinki. Gesamtgerinnung, 'Thromboplastinzeit (Quick), Plasmafaktoren, Gefäßfaktoren; Thrombozyten: Zahl und Faktoren, Fibrinogen, Fibrinolyse. II. Pathologie der Blutgerinnung ("Geburtsblutungen«). Hauptreferat: C. L. Schneider-Eggström, Dearborn/Michigan. Pathogenese, Diagnostik, Therapie. Anfragen an den Präsidenten, Prof. Dr. Runge, Univ.-Frauenklinik, Heidelberg.

\title{
Berichtigung zur Arbeit
}

„Die Verwendbarkeit der passiven oder indirekten Hämagglutinationsreaktion nach Boyden beim Nachweis von Antikörpern“

von F. Scheiffarth und W. Frenger.

B 1 u t 2, 102-107 (1956).

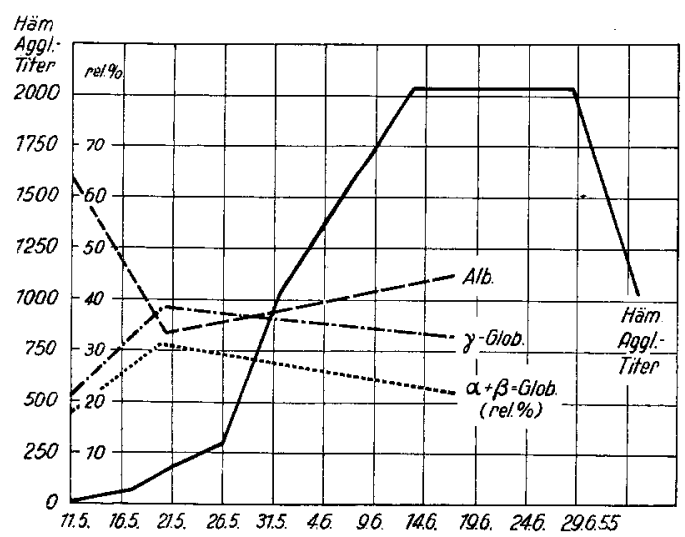

Abb. 1 zeigt am Modell des Serums eines mit Pferdeserum immunisierten Kaninchens das Verhalten des Hämagglutinationstiters während des Immunisierungsprozesses.

Es ergibt sich daraus, daß keine exakten quantitativen Beziehungen zwischen dem Hämagglutinationstiter und der Höhe der einzelnen Serumproteinfraktionen bestehen. 


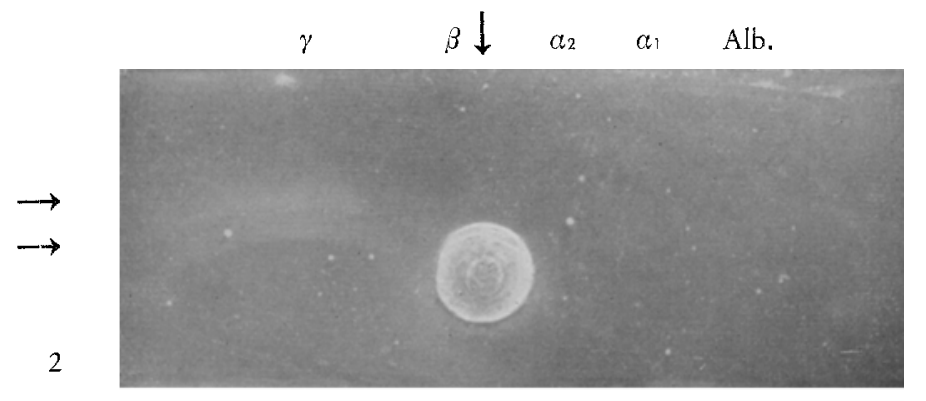

Immuno-

Elektro-

phorese

16. 6.55

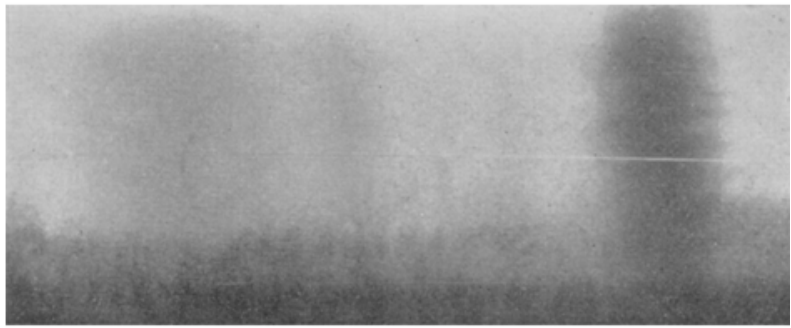

Agglut.-

Elektro-

phorese

16.6. 55

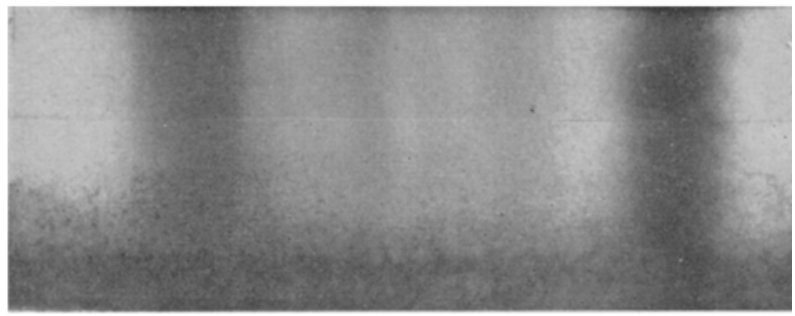

Agglut.-

Elektro-

phorese

20. 5.55

Die Teilabb. 2, 3 und 4 zeigen dazu ergänzend, daß zu Beginn des Immunisierungprozesses zwar der Anstieg einzelner Serumglobulinfraktionen, insbesondere der $\gamma$-Globulinfraktion, bereits beträchtlich, der Antikörpergehalt, grob gemessen neben dem Agglutinationstiter mit der Immuno- und Agglutinationselektrophorese, jedoch noch gering ist. Auf der Höhe des Hämagglutinationstiters bzw. bei größtem Antikörpergehalt sind dagegen die entsprechenden Serumglobulinfraktionen bereits deutlich abgefallen.

$A b b, 2$ zeigt die Immunoelektrophorese auf der Höhe des Hämagglutinationstiters. Die ringförmige Vertiefung in der Mitte der Gelplatte entspricht der Inkubationsstelle des Antiserums $(\uparrow)$. Der Serumgammaglobulinfraktion entsprechend finden sich mehrere Präzipitationslinien $(\vec{\rightarrow})$, die nach Berührung des antikörperhaltigen Serums mit dem an der Längsseite der Gelplatte aufgetragenen Antigen entstanden sind.

$A b b .3$ und 4 stellen die Agglutinationselektrophorese auf der Höhe und zu Beginn des Agglutinationstiters dar.

Seite 103: Die 12. und 13. Zeile von unten muß wegfallen. (»Lediglich bei der Verwendung eines, wie erwähnt, natürlich vorher komplettierten Haptens als Antigen wird intaktes Komplement gebraucht. «)

Seite 103, 5. Zeile von unten, ist einzusetzen: Unspezifische Agglutionationsphänomene, die gelegentlich, insbesondere bei Verwendung von Serum mit erheblicher Dysproteinämie (Lebercirrhose, Nephrose, Myelom, chron.-entzündliche Zustände) oder beim Vorliegen von Kryoglobulinen auftreten können, wie wir es verschiedentlich gesehen haben, sind durch entsprechende Kontrollen auszuschließen. Dabei sollte stets eine Titerbestimmung in der Antiserum-Verdünnungsreihe angestrebt werden, was jedoch nur möglich wird, wenn das Antigen quantitativ exakt meßbar ist.

Seite 104: Das Wort »Ergebnisse« entfällt. 